\title{
Relationship between residual feed intake and digestibility for lactating Holstein cows fed high and low starch diets
}

\author{
S. B. Potts, J. P. Boerman, A. L. Lock, M. S. Allen, and M. J. VandeHaar ${ }^{1}$ \\ Department of Animal Science, Michigan State University, East Lansing 48824
}

\begin{abstract}
We determined if differences in digestibility among cows explained variation in residual feed intake (RFI) in 4 crossover design experiments. Lactating Holstein cows $(\mathrm{n}=109 ; 120 \pm 30 \mathrm{~d}$ in milk; mean $\pm \mathrm{SD})$ were fed diets high (HS) or low (LS) in starch. The HS diets were $30 \%( \pm 1.8 \%)$ starch and $27 \%( \pm 1.2 \%)$ neutral detergent fiber (NDF); LS diets were $14 \%( \pm 2.2 \%)$ starch and $40 \%( \pm 5.3 \%)$ NDF. Each experiment consisted of two 28-d treatment periods, with apparent total-tract digestibility measured using indigestible NDF as an internal marker during the last $5 \mathrm{~d}$ of each period. Individual cow dry matter (DM) intake and milk yield were recorded daily, body weight was measured 3 to 5 times per week, and milk components were analyzed $2 \mathrm{~d} /$ wk. Individual DM intake was regressed on milk energy output, metabolic body weight, body energy gain, and fixed effects of parity, experiment, cohort (a group of cows that received treatments in the same sequence) nested within experiment, and diet nested within cohort and experiment, with the residual being RFI. High RFI cows ate more than expected and were deemed less efficient. Residual feed intake correlated negatively with digestibility of starch for both HS $(\mathrm{r}=-0.31)$ and LS $(\mathrm{r}=-0.23)$ diets, and with digestibilities of DM ( $\mathrm{r}$ $=-0.30)$ and NDF $(r=-0.23)$ for LS diets but was not correlated with DM or NDF digestibility for HS diets. For each cohort within an experiment, cows were classified as high RFI (HRFI; >0.5 SD), medium RFI (MRFI; $\pm 0.5 \mathrm{SD}$ ), and low RFI (LRFI; <-0.5 SD). Digestibility of DM was similar $(\sim 66 \%)$ among HRFI and LRFI for HS diets but greater for LRFI when fed LS diets (64 vs. $62 \%$ ). For LS diets, digestibility of DM could account for up to $31 \%$ of the differences among HRFI and LRFI for apparent diet energy density, as determined from individual cow performance, indicating that digestibility explains some of the between-animal differences for the ability to convert gross energy into
\end{abstract}

Received March 21, 2016.

Accepted August 9, 2016.

${ }^{1}$ Corresponding author: mikevh@msu.edu net energy. Some of the differences in digestibility between HRFI and LRFI were expected because cows with high RFI eat at a greater multiple of maintenance, and greater intake is associated with increased passage rate and digestibility depression. Based on these data, we conclude that a cow's digestive ability explains none of the variation in RFI for cows eating high starch diets but 9 to $31 \%$ of the variation in RFI when cows are fed low starch diets. Perhaps differences in other metabolic processes, such as tissue turnover, heat production, or others related to maintenance, can account for more variation in RFI than digestibility.

Key words: digestibility depression, feed efficiency, dry matter intake

\section{INTRODUCTION}

Residual feed intake (RFI) has been used to assess feed efficiency in beef cattle (Richardson et al., 2004; Nkrumah et al., 2006; Lawrence et al., 2011), swine (Harris et al., 2012), poultry (Luiting et al., 1994; Mignon-Grasteau et al., 2004), and dairy cattle (Rius et al., 2012; Tempelman et al., 2015; VandeHaar et al., 2016). Residual feed intake is a tool used to evaluate feed efficiency and is the difference between what an animal consumes and what it is predicted to consume (Koch et al., 1963); it quantifies feed efficiency within a production level so it is independent of the dilution of maintenance as determined on a requirement basis. Within a given production level, cows with low RFI are deemed more efficient because they eat less than contemporaries. Low RFI cows are able to convert gross energy to net energy more efficiently because they have improved digestive and metabolic efficiencies, or have lower maintenance requirements than expected for a given $\mathrm{BW}$.

The relative contributions of the specific biological mechanisms that explain differences in RFI among animals are not clear. For finishing beef steers, Richardson and Herd (2004) hypothesized that variation in RFI was due to feeding patterns (2\%), activity level (10\%), protein turnover and tissue metabolism (37\%), body composition (5\%), heat increment of feeding (9\%), 
digestibility (10\%), and other undefined metabolic processes $(27 \%)$. Total-tract digestibility is a reflection of both diet digestibility and the digestive ability of the animal. Animals with greater digestive ability lose less energy in feces and are expected to be more energetically efficient than contemporaries consuming the same diet. Previous studies in dairy heifers (Rius et al., 2012) and beef steers (Richardson et al., 1996; Nkrumah et al., 2006) have demonstrated that animals classified as low RFI also had improved digestibility. Additionally, broilers selected divergently for digestive efficiency differed in RFI, with broilers of the high digestive efficiency line having lower RFI than birds of the low digestive efficiency line (Mignon-Grasteau et al., 2004).

Differences in digestibility between high and low RFI animals may be dependent on the type of diet the animal consumes. Rougière et al. (2009) studied lines of broilers selected for digestive efficiency, which were also divergent for RFI, and determined that feeding diets of coarse particle size that increased gut retention time resulted in improved digestibility for the low but not the high digestive efficiency line. Hernandez-Sanabria et al. (2012) showed that the proportion of Eubacterium sp. in rumen fluid samples differed between high and low RFI cattle when a $100 \%$ concentrate diet was fed, but not when an $80 \%$ concentrate diet was fed. In contrast, Carberry et al. (2012) observed stronger relationships between RFI and rumen microbial population proportions when cattle were fed a high forage (100\%) compared with a low forage (30\%) diet. Both of these studies suggest that the relationship between RFI and rumen microbial communities, and thus ruminal digestion, may be affected by the type of diet fed.

We hypothesized that (1) digestibility would account for some of the variation in RFI and that low RFI cows would have improved digestibility compared with high RFI cows, and (2) this relationship would differ for diets high compared with low in starch. Our objective in the present study was to determine if digestibility accounts for variation in RFI in lactating dairy cows fed high (HS) and low (LS) starch diets.

\section{MATERIALS AND METHODS}

\section{Cows, Experimental Design, and Diets}

Experimental procedures were approved by the Institutional Animal Care and Use Committee of Michigan State University. Data from 4 separate crossover experiments, described by Potts et al. (2015), were used to determine the relationship between RFI and digestibility. Lactating Holstein cows were fed diets that differed in starch concentration in experiments 1 $(\mathrm{n}=32), 2(\mathrm{n}=25), 3(\mathrm{n}=32)$, and $4(\mathrm{n}=20)$. Treat- ment effects for experiments 1 and 3 are reported in separate publications (Boerman et al., 2015a,b). Cows $(\mathrm{n}=109)$ averaged (mean \pm SD) $120 \pm 30$ DIM, $42 \pm 9$ $\mathrm{kg}$ of milk/d, and $665 \pm 77 \mathrm{~kg}$ of BW at the beginning of the experiments. Each experiment consisted of two 28-d treatment periods during which HS or LS diets were fed. Prior to the first treatment period in each experiment, cows were fed a common diet for 14, 5, 7 , and $3 \mathrm{~d}$ for experiments $1,2,3$, and 4 , respectively. Cows were blocked based on pre-treatment-period milk yield and parity and randomly assigned to treatment sequence. Cows were housed in individual tie stalls and milked twice daily (0300 and $1430 \mathrm{~h}$ ) in a milking parlor. Water was available ad libitum, and tie stalls were equipped with a double-cupped watering system to prevent contamination of feed with water and a front gate to prevent other cows from stealing feed during cow movements to and from the milking parlor.

During each experiment, cows were fed HS or LS diets (Table 1). On average, HS diets were $30 \%( \pm 1.8 \%)$ starch and $27 \%( \pm 1.2 \%) \mathrm{NDF}$, and contained 30 to $35 \%$ corn grain; LS diets were $14 \%( \pm 2.2 \%)$ starch and $40 \%( \pm 5.3 \%) \mathrm{NDF}$, with soybean hulls replacing a proportion of corn grain. In experiment 3, the LS diet also contained a fat supplement and more legume silage than HS. In experiments 2 and 4, LS diets contained less forage than HS. Diets were adjusted for changes in forage DM concentration twice weekly.

\section{Data and Sample Collection}

Cows were fed once daily at $1000 \mathrm{~h}$ (experiments 2 and 4) or $1200 \mathrm{~h}$ (experiments 1 and 3) for $>110 \%$ of expected intake based on intake from the previous day, and orts were removed and weighed daily before feeding. Milk yield was recorded electronically at each milking and milk samples were obtained from 4 consecutive milkings per week. Milk samples were analyzed for fat, true protein, lactose, somatic cells, and milk urea nitrogen with infrared spectroscopy (AOAC, 1990; method 972.160) by Michigan DHIA (Universal Lab Services, Lansing, MI). Body weight for each cow was recorded 3 (experiments 2, 3, and 4) or 5 (experiment 1) times per week immediately after the morning milking. Body condition score was determined on a 5-point scale in 0.25 -unit increments, where $1=$ thin and $5=$ fat, as described by Wildman et al. (1982), by 3 trained investigators and recorded for each cow at the beginning and end of each period.

Sampling procedures were the same for all 4 experiments. Samples of feces, orts, and feed ingredients were collected during the last $5 \mathrm{~d}$ of each treatment period to estimate nutrient digestibility. Samples of feces were collected every $15 \mathrm{~h}$ (2400, 0230, 0600, 0900, 1200, 1500, 
Table 1. Composition of high (HS) and low (LS) starch diets fed during each experiment

\begin{tabular}{|c|c|c|c|c|c|c|c|c|}
\hline \multirow[b]{2}{*}{ Item } & \multicolumn{2}{|c|}{ Experiment 1} & \multicolumn{2}{|c|}{ Experiment 2} & \multicolumn{2}{|c|}{ Experiment 3} & \multicolumn{2}{|c|}{ Experiment 4} \\
\hline & HS & LS & HS & LS & HS & $\mathrm{LS}$ & HS & LS \\
\hline Corn silage & 23.9 & 24.3 & 23.6 & 23.8 & 23.7 & 24.2 & 23.5 & 20.9 \\
\hline Legume silage & 21.9 & 22.1 & 21.2 & 21.4 & 11.1 & 22.6 & 20.6 & 18.4 \\
\hline Wheat straw & 4.97 & 5.04 & 5.19 & - & 3.79 & 1.94 & 4.82 & - \\
\hline Soybean hulls & - & 28.9 & - & 30.5 & - & 10.6 & - & 32.1 \\
\hline Corn, ground high moisture & - & - & 8.28 & 8.16 & 21.5 & 11.0 & - & - \\
\hline Soybean meal, $48 \%$ & 16.6 & 13.5 & 17.2 & 12.9 & 15.9 & 14.6 & 17.2 & 9.08 \\
\hline Fat supplement ${ }^{1}$ & - & - & - & - & - & 2.51 & - & - \\
\hline Vitamin and mineral $^{2}$ & 2.03 & 2.06 & 2.06 & 2.09 & 2.02 & 2.05 & 2.08 & 2.08 \\
\hline Limestone & 0.50 & - & 0.50 & - & 0.75 & 0.76 & 0.52 & - \\
\hline Sodium bicarbonate & 0.51 & 0.52 & 0.49 & 0.50 & 0.75 & 0.76 & 0.51 & 0.51 \\
\hline Dicalcium phosphate & - & 0.25 & 0.18 & 0.50 & - & - & - & 0.51 \\
\hline $\mathrm{NFC}^{4}$ & 47.9 & 32.2 & 48.6 & 35.4 & 48.7 & 35.9 & 47.0 & 30.7 \\
\hline Soluble fiber ${ }^{5}$ & 12.8 & 15.5 & 13.6 & 15.8 & 12.3 & 15.1 & 14.0 & 14.8 \\
\hline Sugar ${ }^{6}$ & 1.08 & 0.57 & 0.92 & 0.24 & 1.06 & 0.79 & 1.09 & 0.81 \\
\hline $\mathrm{CP}$ & 16.4 & 15.9 & 16.6 & 16.0 & 17.0 & 18.3 & 16.9 & 15.2 \\
\hline Ash & 5.9 & 6.4 & 6.5 & 7.3 & 5.4 & 6.8 & 6.1 & 6.5 \\
\hline Ether extract & 2.52 & 1.90 & 2.15 & 1.95 & 3.24 & 5.61 & 2.30 & 3.41 \\
\hline Organic acid ${ }^{6}$ & 3.88 & 3.93 & 3.79 & 3.84 & 2.90 & 3.97 & 3.74 & 3.33 \\
\hline NDF:starch & 0.90 & 3.60 & 0.85 & 2.54 & 0.77 & 2.04 & 0.98 & 3.75 \\
\hline $\mathrm{NE}_{\mathrm{L}},{ }^{7}$ Mcal $/ \mathrm{kg}$ & 1.62 & 1.56 & 1.68 & 1.62 & 1.80 & 1.75 & 1.72 & 1.62 \\
\hline $\mathrm{GE},{ }^{8} \mathrm{Mcal} / \mathrm{kg}$ & 4.20 & 4.16 & 4.16 & 4.11 & 4.26 & 4.34 & 4.19 & 4.21 \\
\hline
\end{tabular}

${ }^{1}$ Fat: $85 \%$ palmitic acid enriched free fatty acid supplement (BergaFat F-100, Berg and Schmidt America LLC, Libertyville, IL).

${ }^{2}$ Vitamin and mineral mix contained $34.1 \%$ dry ground shell corn, $25.6 \%$ white salt, $21.8 \%$ calcium carbonate, $9.1 \%$ Biofos (The Mosaic Co., Plymouth, MN), $3.9 \%$ magnesium oxide, $2 \%$ soybean oil, and $<1 \%$ of each of the following: manganese sulfate, zinc sulfate, ferrous sulfate, copper sulfate, iodine, cobalt carbonate, vitamin E, vitamin A, vitamin D, and selenium.

${ }^{3}$ Nutrient composition was determined from feed ingredients sampled during the last $5 \mathrm{~d}$ of each 28 -d experimental period.

${ }^{4} \mathrm{NFC}$ calculated as $100-(\mathrm{NDF} \%+\mathrm{CP} \%+$ ash $\%+$ fatty acid\%) according to NRC (2001).

${ }^{5}$ Soluble fiber calculated as NFC $\%-(\operatorname{starch} \%+$ organic acid $\%+\operatorname{sugar} \%)$.

${ }^{6}$ Estimated from Spartan Dairy Ration Evaluator (version 3.0, Michigan State University, East Lansing).

${ }^{7}$ Mean apparent net energy concentration of diets, based on average cow performance. For each diet, DietNE $E_{\mathrm{L}}=$ the average of $(\mathrm{MilkE}+0.08$ $\times \mathrm{MBW}+\Delta$ BodyE) $/ \mathrm{DMI}$ for all cows on the diet, where MilkE $=$ milk energy output, $\mathrm{MBW}=$ metabolic BW, and $\Delta \mathrm{BodyE}=$ body energy change.

${ }^{8}$ Gross energy concentration, calculated from nutrient profile of individual feed ingredients: $4.20 \mathrm{kcal} / \mathrm{g}$ of carbohydrate, $5.65 \mathrm{kcal} / \mathrm{g}$ of CP, 9.50 $\mathrm{kcal} / \mathrm{g}$ of fatty acid (estimated as ether extract - 1; NRC, 2001), $3.95 \mathrm{kcal} / \mathrm{g}$ of sugar (Merrill and Watt, 1973).

1800, $2100 \mathrm{~h}$ ) to obtain 8 samples per cow to represent every $3 \mathrm{~h}$ of a day to account for diurnal variation. Samples of diet ingredients $(\sim 0.5 \mathrm{~kg})$ and orts from each cow (12.5\% of the amount) were obtained each day during the 5 -d collection periods. All samples were stored at $-20^{\circ} \mathrm{C}$ until analysis.

\section{Sample Analysis}

Sample analyses were the same for all 4 experiments. For each experiment, diet ingredient and orts samples were composited by period. Diet ingredients, orts, and feces were dried in a forced-air oven $\left(55^{\circ} \mathrm{C}\right.$ for $\left.72 \mathrm{~h}\right)$ before grinding through a Wiley mill (1-mm screen, Ar- thur H. Thomas Co., Philadelphia, PA). Feces obtained from a cow during a period were composited on an equal DM basis. Samples of diet ingredients, orts, and feces were analyzed for $\mathrm{CP}$, starch, NDF, indigestible $\mathrm{NDF}$, and ash. Diet ingredients were also analyzed for ether extract, which was determined using a modified Soxhlet apparatus (AOAC, 1990). Crude protein was determined according to Hach et al. (1987). Starch was analyzed by an enzymatic method after gelatinization with sodium hydroxide (Karkalas, 1985). Subsequently, glucose concentration was determined via glucose oxidase method (Glucose kit \#510, Sigma Chemical Co., St. Louis, MO) and absorbance was measured with a micro-plate reader (SpectraMax 190, Molecular De- 
vices Corp., Sunnyvale, CA). Neutral detergent fiber and indigestible NDF were determined according to Mertens (2002) and Goering and Van Soest (1970), respectively. Indigestible NDF, which was used as an internal marker to estimate fecal output and nutrient digestibility (Cochran et al., 1986), was estimated as NDF residue after $240 \mathrm{~h}$ of in vitro fermentation (Goering and VanSoest, 1970); flasks were re-inoculated at $120 \mathrm{~h}$ to ensure a viable microbial population. Rumen fluid for the in vitro incubations was collected from a nonpregnant dry cow fed only dry hay. Ash was determined after $5 \mathrm{~h}$ combustion at $500^{\circ} \mathrm{C}$. Concentrations of nutrients are expressed as a percentage of DM.

\section{Calculations}

Milk energy output (MilkE; Mcal/d) for a cow was estimated according to NRC (2001; Equation 2-15) with the adjusted coefficient for true protein instead of CP:

$$
\begin{aligned}
\text { MilkE }=9.29 \times \text { fat }(\mathrm{kg})+5.63 \times \text { true protein }(\mathrm{kg}) \\
+3.95 \times \text { lactose }(\mathrm{kg}),
\end{aligned}
$$

where each component is based on the average output of a cow during a 28-d treatment period. Metabolic BW for a cow (MBW; $\mathrm{kg}^{0.75}$ ) was estimated as $\mathrm{BW}^{0.75}$, where $\mathrm{BW}$ is the mean $\mathrm{BW}$ for the cow during a specified treatment period. Body weight change $(\Delta \mathbf{B W}$; $\mathrm{kg} / \mathrm{d}$ ) was calculated for individual cows within a period by regressing $\mathrm{BW}$ (20 records per cow per period in experiment 1 and 12 records per cow per period in experiments 2, 3, and 4) against time. For each cow, BW records that were $>3.5$ SD from this regression line were identified as outliers and removed; this process was repeated twice. The slope of the third regression for each individual cow within a period was used to define her $\triangle \mathrm{BW}$ within that period. In total, $2,2,8$, and $3 \mathrm{BW}$ measurements (all from different cows) were removed during this process for experiments $1,2,3$, and 4 , respectively. Energy for body tissue gain ( $\boldsymbol{\Delta B o d y E}$; $\mathrm{Mcal} / \mathrm{d}$ ) was estimated by an equation derived from NRC (2001; Table 2-5):

$$
\Delta \text { BodyE }=(2.88+1.036 \times \mathrm{BCS}) \times \Delta \mathrm{BW},
$$

where BCS is the average BCS for a cow during a 28-d treatment period.

The milk:feed ratio for a cow during a period was determined as the average daily ECM yield $\{\mathrm{ECM}$ $=[0.327 \times$ milk $(\mathrm{kg})+12.95 \times$ fat $(\mathrm{kg})+7.20 \times$ protein (kg)]; Tyrrell and Reid, 1965\} over the average daily DMI. Gross efficiency, or the percent of consumed energy captured in milk and body tissue gain, was cal- culated as the sum of the average MilkE and $\triangle$ BodyE divided by the average gross energy intake during a 28-d treatment period. Individual feed nutrient analyses were used to calculate diet gross energy content, with sugar and organic acid content of feeds being estimated from Spartan Dairy Ration Evaluator (version 3.0, Michigan State University, East Lansing, MI). Energy values for each nutrient were assigned according to Merrill and Watt (1973): $4.20 \mathrm{kcal} / \mathrm{g}$ of carbohydrate, $5.65 \mathrm{kcal} / \mathrm{g}$ of CP, $9.50 \mathrm{kcal} / \mathrm{g}$ of fat (estimated as ether extract - 1; NRC, 2001), $3.95 \mathrm{kcal} / \mathrm{g}$ of sugar, and 3.62 $\mathrm{kcal} / \mathrm{g}$ of fermented acid. Apparent diet energy density $\left(\right.$ DietNE $E_{L} ; \mathrm{Mcal} / \mathrm{kg}$ ) was calculated for each cow when fed each diet as

$\operatorname{DietNE}_{\mathrm{L}}=(\mathrm{MilkE}+0.08 \times \mathrm{MBW}+\Delta$ BodyE $) /$ DMI

Multiple of maintenance (MM) was calculated 2 ways: (1) based on NRC (2001) requirements for observed production and (2) based on observed intake and the NRC (2001) maintenance requirement. Multiple of maintenance based on NRC (2001) requirements for observed production $\left(\mathbf{M M}_{\mathbf{R}}\right)$ was calculated as

$$
\begin{gathered}
\mathrm{MM}_{\mathrm{R}}=(\text { MilkE }+0.08 \times \mathrm{MBW}+\Delta \text { BodyE }) / \\
(0.08 \times \mathrm{MBW}) .
\end{gathered}
$$

Multiple of maintenance based on observed intake $\left(\mathbf{M M}_{\mathbf{I}}\right)$ was calculated as

$$
\mathrm{MM}_{\mathrm{I}}=\left(\mathrm{DMI} \times \text { mean } \operatorname{DietNE} \mathrm{L}_{\mathrm{L}}\right) /(0.08 \times \mathrm{MBW}),
$$

where mean DietNE $\mathrm{L}_{\mathrm{L}}$ was either 1.7 or $1.6 \mathrm{Mcal}$ of $\mathrm{NE}_{\mathrm{L}} /$ $\mathrm{kg}$, which was the average apparent $\operatorname{DietNE}_{\mathrm{L}}$ for $\mathrm{HS}$ and LS across all 4 experiments, respectively (Table 1).

\section{Statistical Analysis}

Data from all 4 experiments were compiled for analysis. Two cows from experiment 3 were not included in the analysis due to a displaced abomasum and severe mastitis infection during the 5 -d collection of periods 1 and 2 , respectively. Dry matter intake for an individual cow during each 28-d treatment period was regressed as a function of major energy sinks using GLM Procedure in SAS (version 9.3, SAS Institute Inc., Cary, NC). To define RFI, DMI was modeled as

$$
\begin{gathered}
\mathrm{DMI}_{\mathrm{i}}=\beta_{0}+\beta_{1} \times \text { MilkE }_{\mathrm{i}} \\
+\beta_{2} \times \mathrm{MBW}_{\mathrm{i}}+\beta_{3} \times \Delta \text { BodyE }_{\mathrm{i}}+\text { parity } \\
+ \text { experiment }+ \text { cohort }(\text { experiment }) \\
+\operatorname{diet}(\text { cohort } \times \text { experiment })+\varepsilon_{\mathrm{i}},
\end{gathered}
$$


where $\mathrm{DMI}_{\mathrm{i}}$ is the mean DMI observed or the ith cow; $\beta_{0}$ is the intercept; and $\beta_{1}, \beta_{2}$, and $\beta_{3}$ are the coefficients associated with the mean $\mathrm{MilkE}_{\mathrm{i}}, \mathrm{MBW}_{\mathrm{i}}$, and $\triangle$ BodyE $_{\mathrm{i}}$ observed for the ith cow, respectively. Parity (1 or $2+$ ), experiment $(1,2,3$, or 4$)$, cohort (1 or 2$)$ within experiment, and diet (HS or LS) within cohort and experiment were fixed effects, where a cohort was defined as a group of cows that received treatments in the same sequence (i.e., HS then LS or LS then HS). The error term in the model was used to define RFI. To determine if DM digestibility could account for some of the residual in model 1, we also regressed DMI as in model 1 with the addition of DM digestibility and the interaction of DM digestibility and diet (HS or LS) as covariates:

$$
\begin{gathered}
\text { DMI }_{\mathrm{i}}=\beta_{0}+\beta_{1} \times \text { MilkE }_{\mathrm{i}}+\beta_{2} \times \mathrm{MBW}_{\mathrm{i}} \\
+\beta_{3} \times \Delta \text { BodyE }_{\mathrm{i}}+\text { parity }+ \text { experiment } \\
+ \text { cohort }(\text { experiment })+\operatorname{diet}(\text { cohort } \times \text { experiment }) \\
+ \text { DM digestibility }+ \text { DM digestibility } \times \operatorname{diet}+\varepsilon_{\mathrm{i}} \cdot \quad[2]
\end{gathered}
$$

The interaction between DM digestibility and diet was included to determine if the effect of DM digestibility varied by diet. For our analysis, RFI was determined using model 1.

Cows were grouped based on RFI status and classified as high RFI (HRFI), low RFI (LRFI), or medium RFI (MRFI). Cows with RFI $>0.5 \mathrm{SD}$ of the mean RFI for a cohort within an experiment were considered HRFI, those $<-0.5 \mathrm{SD}$ of the mean were considered LRFI, and those within $\pm 0.5 \mathrm{SD}$ of the mean were considered MRFI. The effect of RFI group (HRFI, MRFI, or LRFI) was determined using the MIXED Procedure of SAS according to a model that included the fixed effects of RFI group (HRFI, MRFI, or LRFI) and experiment $(1,2,3$, or 4$)$, their interaction, and the random effect of cow nested within experiment. Additionally, to account for differences in feed intake as a multiple of maintenance $\left(\mathrm{MM}_{\mathrm{I}}\right)$ among RFI groups, nutrient digestibilities were analyzed according to a mixed model that included the fixed effects of RFI group (HRFI, MRFI, or LRFI) and experiment $(1,2,3$, or 4$), \mathrm{MM}_{\mathrm{I}}$ as a covariate, all 2- and 3-way interactions, and the random effect of cow nested within experiment. For both mixed models, Tukey's test was used to investigate differences of least squares means. Prior to analysis, the cohort mean nutrient digestibilities were adjusted to the overall mean nutrient digestibilities for HS or LS across all 4 experiments. The REG Procedure was used to determine regression equations, and Pearson correlations were obtained using the CORR Procedure of SAS. For relationships among nutrient digestibilities and RFI, partial correlations, which accounted for effects of parity, cohort, and experiment, were obtained using the PARTIAL option of the CORR Procedure.

Production, efficiency (milk:feed, gross efficiency, and RFI), and digestibility responses to HS and LS diets were analyzed using a mixed model that included the fixed effects of experiment $(1,2,3$, or 4$)$, diet (HS or LS), period (1 or 2 ) nested within experiment, parity (1 or $2+)$, all interactions of fixed effects, and the random effect of cow nested within parity and experiment. Main effects and correlations were considered significant at $P<0.05$ and trends at $P<0.10$. Interactions were considered significant at $P<0.10$ and trends at $P<0.15$.

\section{RESULTS AND DISCUSSION}

\section{Performance}

Feeding HS and LS diets resulted in significant variation in feed intake level as indicated by greater $M_{\mathrm{I}}$ and $\mathrm{MM}_{\mathrm{R}}$ for HS diets $(P<0.01$; Table 2). Estimated GE intake was similar $(\sim 107 \mathrm{Mcal} / \mathrm{d} ; P=0.16)$, but $\mathrm{NE}_{\mathrm{L}}$ intake was increased for HS than LS (44 vs. 42 $\mathrm{Mcal} / \mathrm{d} ; P<0.01$ ), which reflects the greater digestibility of HS. The HS diets increased gross efficiency (31 vs. $29 \% ; P<0.01$ ), but milk:feed was not affected by diet type $(P=0.87)$. Gross efficiency is different from milk:feed because it accounts for energy partitioned to both milk and body reserves. That gross efficiency, but not milk:feed, was different between HS and LS suggests that cows partitioned a greater proportion of consumed energy toward body tissue when fed HS. This is supported by a greater body energy change (3.74 vs. $2.16 \mathrm{Mcal} / \mathrm{d} ; P<0.01$ ), but similar MilkE (29.6 vs. $29 \mathrm{Mcal} / \mathrm{d} ; P=0.34)$ such that total energy captured as milk output plus body tissue gain was greater $(P<$ 0.01) for HS compared with LS. Residual feed intake was not different between HS and LS diets, as expected, because diet was included in the regression model for calculating RFI.

Digestibilities of starch and DM were greater for HS diets $(P<0.01)$, but NDF digestibility was greater for LS diets $(P<0.01)$; the latter was expected because LS diets contained more digestible NDF sources than HS diets. Others have also observed greater NDF digestibility when nonforage fiber sources, such as beet pulp or soyhulls, replaced ground or high moisture corn in the diet (Voelker and Allen, 2003; Gencoglu et al., 2010). Similar to our results for DM digestibility, Beckman and Weiss (2005) observed a significant linear increase in DM digestibility as the diet NDF:starch ratio was reduced. Although our NDF:starch ratios for LS diets are larger on average (2.98) than that of the lowest starch 
diet tested in that study (1.27), our NDF:starch ratios for HS were similar (0.88) to those of the high and medium starch diets studied by Beckman and Weiss (0.74 and 0.95; Beckman and Weiss, 2005). For our study, differences in DMI as a multiple of maintenance, energy partitioning, and nutrient digestibilities among HS and LS verify that our diets were distinctly different in their utilization by high producing cows.

Nutrient digestibilities were moderately repeatable across HS and LS diets, as shown in Figure 1. Starch and DM digestibilities when cows were fed LS diets were correlated with starch and DM digestibilities when cows were fed HS diets $(\mathrm{r}=0.31, \mathrm{r}=0.28$; both $P<0.01)$. These results indicate that cows that had greater digestive abilities on HS also had greater digestive abilities for LS diets. Thus, it appears that cows that have superior digestive ability for a given diet will also likely have greater digestive ability when fed other types of diets. Digestibilities of NDF $(\mathrm{r}=0.23 ; P=$ $0.02)$ and $\mathrm{CP}(\mathrm{r}=0.22 ; P=0.02$; data not shown $)$ were less repeatable across HS and LS, which reflects the fact that the ability of the cow to digest of each of these nutrients is more dependent on diet rather than individual cow characteristics.

The HRFI and LRFI cows had similar MilkE, MBW, and $\triangle$ BodyE, but LRFI cows had significantly lower
DMI and significantly greater milk:feed, gross efficiency, and apparent DietNE $\mathrm{L}_{\mathrm{L}}$ than HRFI cows for both diets (Table 3). Multiple of maintenance based on observed intake $\left(\mathrm{MM}_{\mathrm{I}}\right)$ correlated positively with RFI (Figure 2) when cows were fed HS $(\mathrm{r}=0.49 ; P<0.01)$ and LS diets $(\mathrm{r}=0.52 ; P<0.01)$, which was not surprising, because low RFI cows (more efficient) have lower DMI than high RFI cows (less efficient), and $\mathrm{MM}_{\mathrm{I}}$ is based on observed DMI. In contrast, $\mathrm{MM}_{\mathrm{R}}$ was not related to RFI for either diet, as was expected because RFI should not be related to MilkE, MBW, or $\triangle \mathrm{BodyE}$, which are the determinants of $\mathrm{MM}_{\mathrm{R}}(P>0.30$; Figure 2).

\section{Digestibility and RFI}

The relationships between RFI and digestibilities of DM, starch, NDF, and CP are illustrated in Figure 3. Partial correlation coefficients, which represent relationships after correction for effects of experiment, cohort, and parity, are reported throughout the text but were similar to Pearson correlation coefficients. Digestibility of DM correlated negatively with RFI $(\mathrm{r}=-0.30 ; P$ $<0.01)$ for LS diets, but not for HS diets $(\mathrm{r}=-0.01$; $P=0.90$ ); thus, DM digestibility accounted for $9 \%$ of the variation in RFI when cows were fed LS but not HS diets. Furthermore, the LRFI cows had greater DM

Table 2. Production, efficiency, and digestibility for cows $(\mathrm{n}=107)$ fed high (HS) and low (LS) starch diets

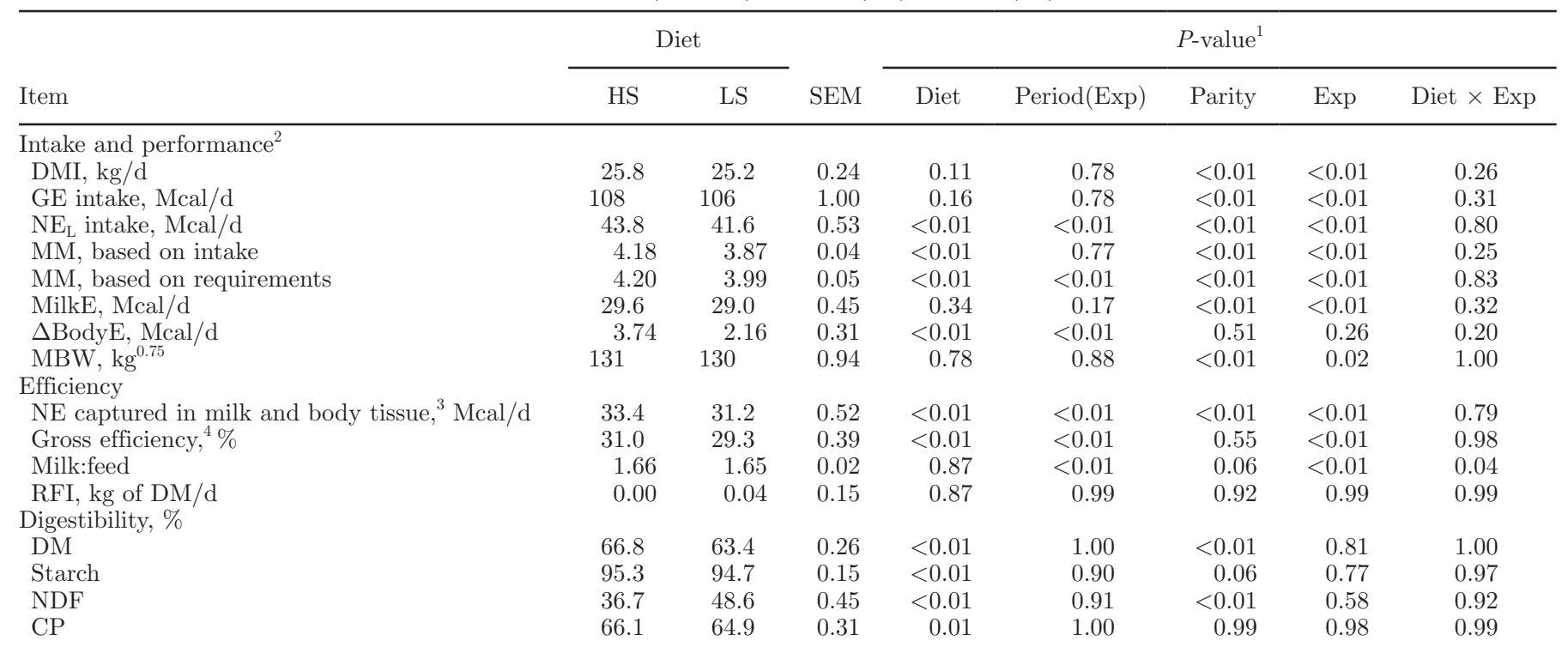

${ }^{1} P$-value associated with fixed effects of diet, period nested within experiment, parity, experiment (exp), and the interaction of diet and experiment.

${ }^{2} \mathrm{GE}$ intake = gross energy intake; $\mathrm{NE}_{\mathrm{L}}$ intake = apparent $\mathrm{NE}_{\mathrm{L}}$ intake based on performance; $\mathrm{MM}=$ multiple of maintenance $($ estimated from requirements for performance or determined from observed intake); MilkE = milk energy output; $\Delta$ BodyE $=$ body energy change; $\mathrm{MBW}=$ metabolic BW.

${ }^{3} \mathrm{NE}$ captured in milk and body tissue $=$ MilkE $+\Delta$ BodyE.

${ }^{4}$ Gross efficiency $=($ MilkE $+\Delta$ BodyE $) /$ GE intake. 

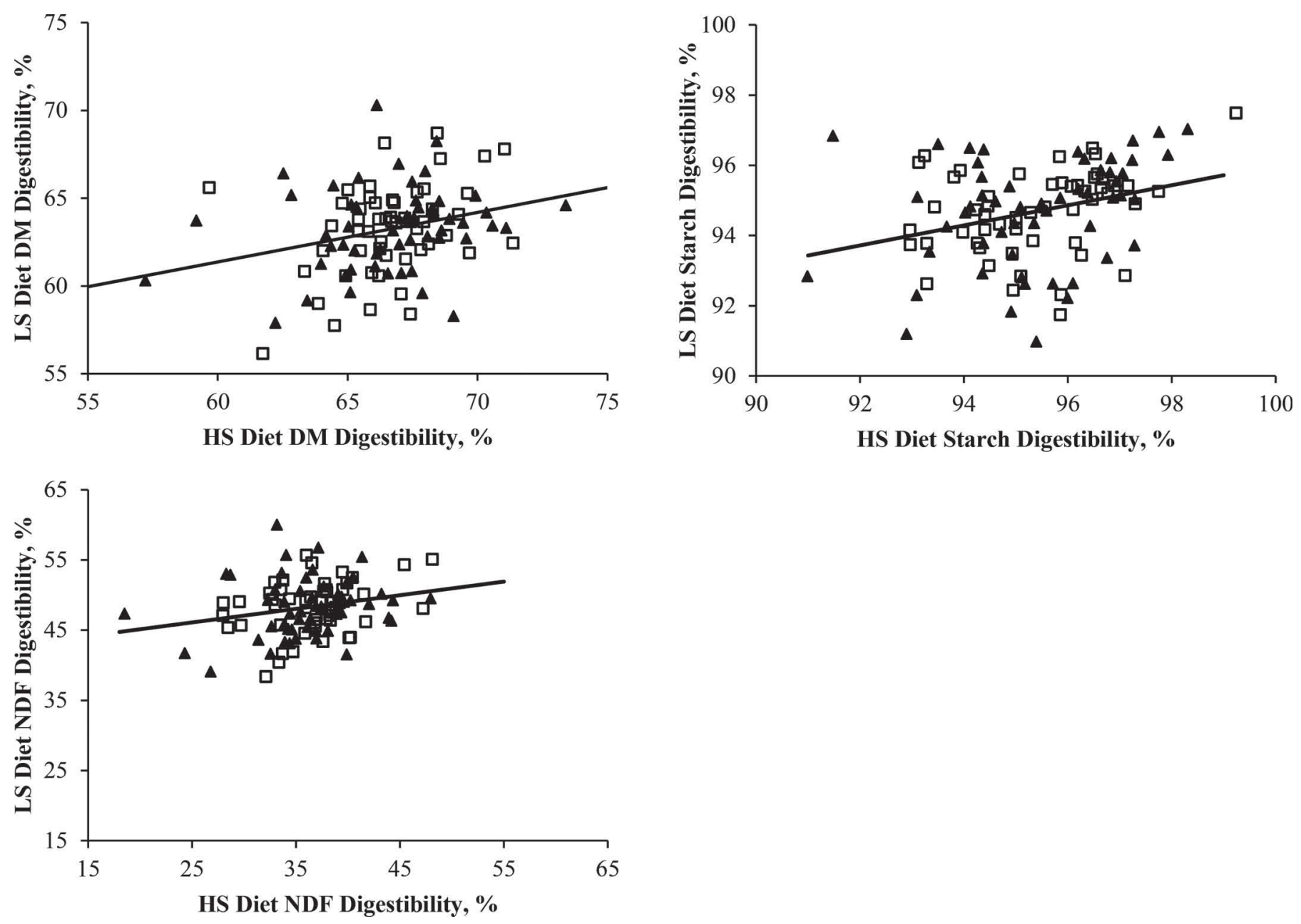

Figure 1. Relationship between nutrient digestibilities when cows $(\mathrm{n}=107)$ were fed high $(\mathrm{HS})$ and low $(\mathrm{LS})$ starch diets. Each point indicates an individual cow and her performance when she was fed each diet. Correlation coefficients were significant for DM $(\mathrm{r}=0.28 ; P<0.01)$, starch $(\mathrm{r}=0.31 ; P<0.01)$, and NDF $(\mathrm{r}=0.23 ; P=0.02)$ digestibilities. Open squares represent cows that received HS and then LS during an experiment; closed triangles represent cows that received LS and then HS during an experiment. These relationships indicate that a cow with low digestibility for one diet also had low digestibility for the other diet.

digestibility than HRFI cows for LS (64.2 vs. $62.4 \%$; $P$ $<0.05$; Table 3). For beef steers fed an $85 \%$ concentrate diet, Richardson and Herd (2004) estimated that 10\% of the variation in RFI was due to digestibility, which is similar to our results for DM digestibility when cows were fed LS. However, this relationship was not apparent when cows were fed HS diets as DM digestibility was similar between LRFI and HRFI cows for HS. This disparity suggests that the relationship between RFI and a cow's digestive ability is dependent on diet type. Similar to our findings for LS diets, others have reported that DM digestibility is greater for low RFI dairy heifers (Rius et al., 2012), beef cattle (Richardson et al., 1996; Nkrumah et al., 2006), and swine (Harris et al., 2012). In contrast, some studies have not shown significant relationships between RFI and DM digest- ibility in beef cattle (Richardson et al., 2004; Lawrence et al., 2011), which is similar to our findings for HS. Discrepancies in this relationship among studies could partially be accounted for by differences in the type of diets fed, as well as physiological state of the animals studied.

Starch digestibility correlated negatively with RFI when cows were fed both HS and LS $(\mathrm{r}=-0.31$ and $\mathrm{r}$ $=-0.23 ; P<0.01$ and $P=0.02$, respectively; Figure 3 ), suggesting that low RFI cows had a greater ability to digest starch irrespective of diet type. However, in contrast to the correlation analysis, starch digestibility was not significantly different among HRFI, MRFI, and LRFI groups (Table 3 ) for LS diets $(P=0.17)$, but tended to be different among RFI groups for HS diets $(P=0.07)$. Digestibilities of NDF and CP correlated 
Table 3. Performance, efficiency, and apparent total-tract digestibility of cows (mean \pm SE; $n=107$ ) fed high and low starch diets by residual feed intake (RFI) grouping ${ }^{1}$

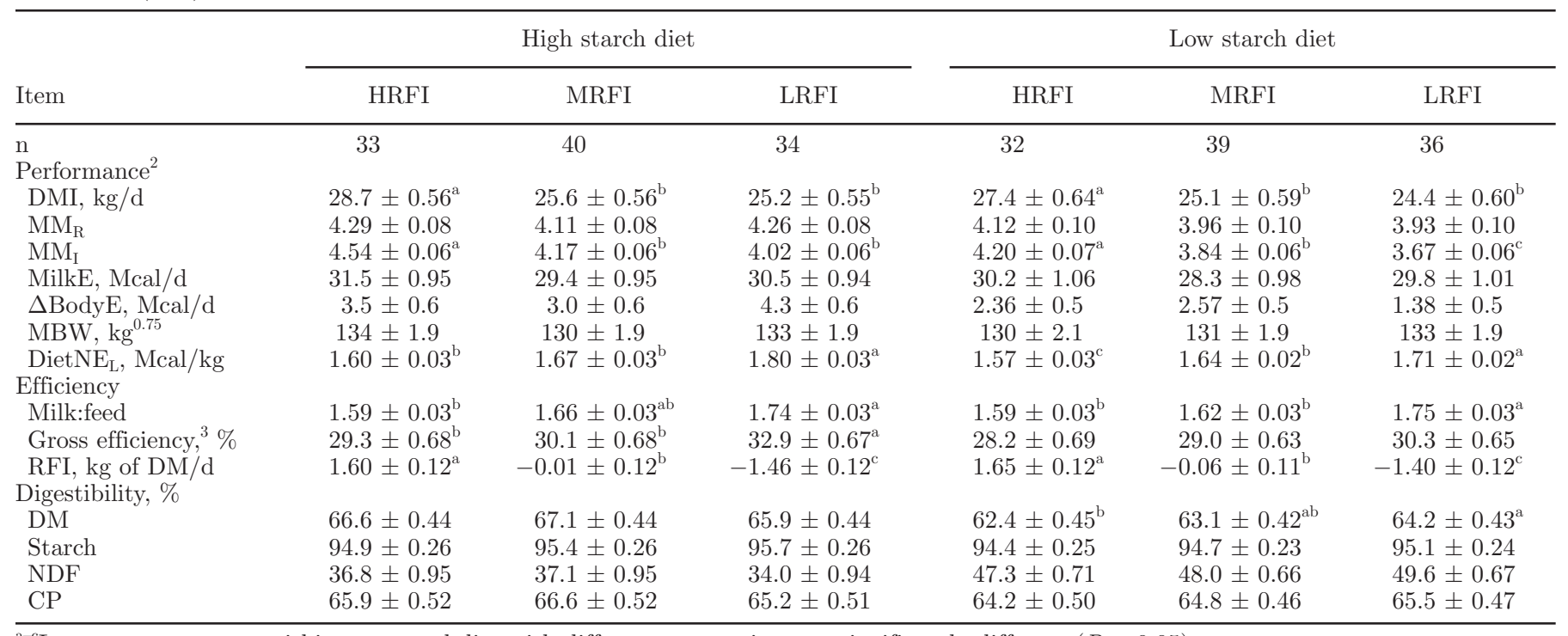

${ }^{\mathrm{a}-\mathrm{c}}$ Least squares means within a row and diet with different superscripts are significantly different $(P<0.05)$.

${ }^{1} \mathrm{HRFI}=$ high RFI cows $(>0.5 \mathrm{SD}), \mathrm{MRFI}=$ medium RFI cows $( \pm 0.5 \mathrm{SD}), \mathrm{LRFI}=$ low RFI cows $(<-0.5 \mathrm{SD})$.

${ }^{2} \mathrm{MM}_{\mathrm{R}}=$ multiple of maintenance estimated from requirements for performance; $\mathrm{MM}_{\mathrm{I}}=$ multiple of maintenance based on observed intake; MilkE = milk energy output; $\Delta$ BodyE = body energy change; $\mathrm{MBW}=$ metabolic $\mathrm{BW} ;$ DietNE $_{\mathrm{L}}=$ apparent energy density of the diet, calculated from mean cow performance for each diet, as (MilkE $+\Delta$ BodyE $+0.08 \times$ MBW) $/ \mathrm{DMI}$ for each cow.

${ }^{3}$ Gross efficiency $=($ MilkE $+\Delta$ BodyE $) /$ GE intake.

negatively with RFI for LS diets $(\mathrm{r}=-0.23$ and $\mathrm{r}=$ -0.23 ; both $P=0.02$, respectively), but not HS diets $(P>0.30$; Figure 3$)$. When HRFI and LRFI groups of cows were compared, digestibility of NDF, but not $\mathrm{CP}$, tended to be significantly greater for the LRFI group fed LS diets (49.6 vs. $47.3 \% ; P=0.05$; Table 3). In contrast to our findings for NDF and CP digestibilities, Nkrumah et al. (2006) observed significantly greater CP digestibility, but not NDF digestibility, for low RFI beef cattle compared with high RFI cattle. Additionally, lactating dairy cattle identified as low RFI heifers had significantly greater nitrogen digestibility, but similar NDF digestibility when compared with high RFI cohorts (Rius et al., 2012).

To determine RFI, DMI was modeled as a function of major energy sinks (model 1); coefficients for MilkE, MBW, and $\triangle$ BodyE were $0.35(P<0.01), 0.09(P$ $<0.01)$, and $0.04(P=0.14)$ and the model $\mathrm{R}^{2}$ and root mean square error were 0.86 and 1.45 , respectively. This model also included effects of parity, experiment, cohort(experiment) and $\operatorname{diet}($ cohort $\times$ experiment), which were also significant $(P \leq 0.01)$. When DM digestibility and its interaction with diet were added as covariates (model 2), we obtained similar coefficients for MilkE, MBW, and $\triangle$ BodyE $(0.33,0.09$, and $0.04 ; P$ $<0.01, P<0.01$, and $P=0.28$, respectively). For that model, coefficients for DM digestibility and DM digest- ibility $\times$ diet were significant $(-0.17$ for DM digestibility, $P=0.04$; 0.17 for DM digestibility for HS diet, $P=$ 0.03 ) and the $R^{2}$ and root mean square error were 0.86 and 1.43 , respectively. Because both DM digestibility and DM digestibility $\times$ diet were significant, and MSE decreased when these covariates were added to the model used to predict DMI (and therefore, derive RFI), these results provide further support for the hypothesis that a cow's digestive ability could contribute to RFI.

We observed that apparent $\operatorname{DietNE}_{\mathrm{L}}$, which was calculated from individual production requirements according to NRC (2001), was greater for the LRFI group for HS (1.80 vs. $1.60 \mathrm{Mcal} / \mathrm{kg} ; P<0.05)$ and LS diets (1.71 vs. $1.57 \mathrm{Mcal} / \mathrm{kg} ; P<0.05$; Table 3 ). Because apparent DietNE $\mathrm{L}_{\mathrm{L}}$ was $8.91 \%$ greater and DM digestibility was $2.75 \%$ greater (64.2 vs. $62.4 \%$; Table 3) for LRFI cows fed LS diets, up to $31 \%$ of the differences $(2.75 \% / 8.91 \%)$ in apparent DietNE $\mathrm{L}_{\mathrm{L}}$ could have been due to differences in DM digestibility. This suggests that differences in digestive ability may partially explain why some animals have a superior ability to extract net energy from their feed. Because digestive ability may account for a portion of the between-animal differences for apparent DietNE $\mathrm{L}_{\mathrm{L}}$, it may also account for differences in RFI. Residual feed intake is essentially an estimate of the efficiency by which cows convert gross energy into net energy, though we realize that 
there are errors associated with determining RFI. For example, it is assumed that the coefficient for calculating maintenance energy requirements from $\mathrm{MBW}$ is 0.08 for every cow; however, this coefficient probably varies greatly among cows, which contributes to RFI.

Variation among HS and LS diets for the relationships between RFI and nutrient digestibilities could be reflective of true differences between animals for digestibility and the ability of some animals to use certain

\section{A}

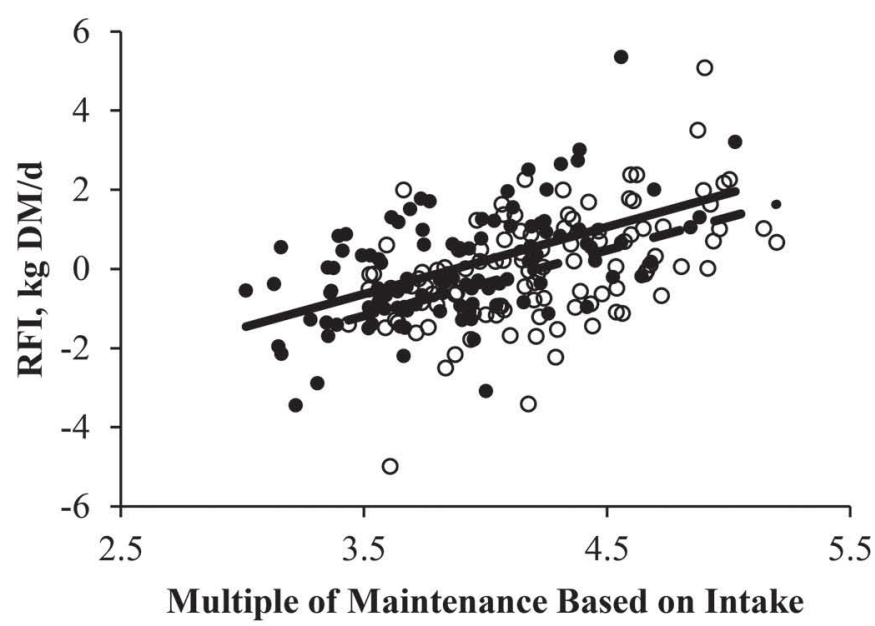

B

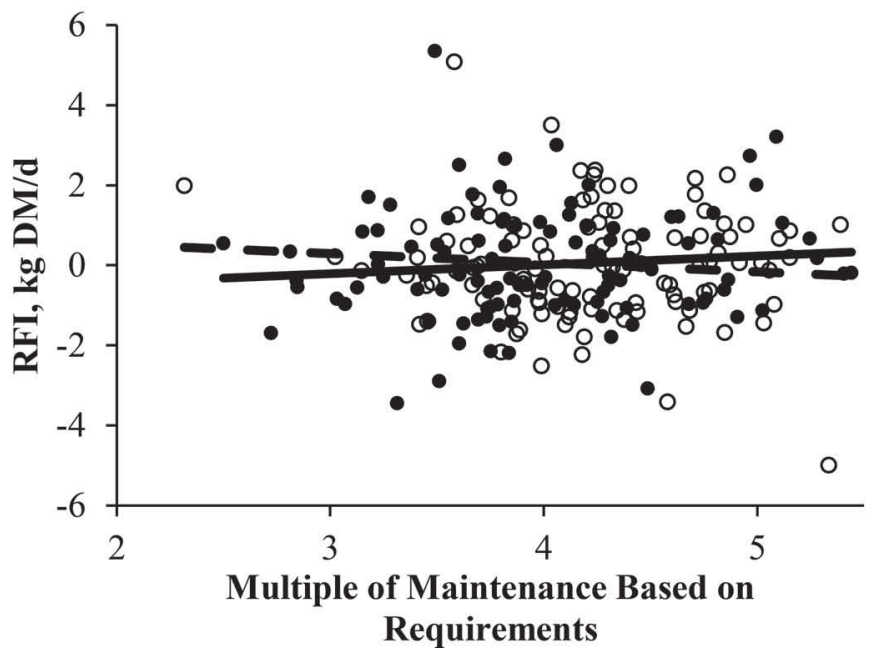

Figure 2. Relationship between residual feed intake (RFI) and (A) multiple of maintenance based on intake (high starch, HS: open circles, dashed line: $\mathrm{kg} / \mathrm{d}=1.66 \mathrm{x}-7.01$; intercept $\mathrm{SE}=1.2$; intercept $P<$ 0.01 ; slope $\mathrm{SE}=0.29$; slope $P<0.01 ; \mathrm{R}^{2}=0.24$; low starch, LS: closed circles, solid line: $\mathrm{kg} / \mathrm{d}=1.70 \mathrm{x}-6.58$; intercept $\mathrm{SE}=1.0$; intercept $P<0.01$; slope $\mathrm{SE}=1.7$; slope $\left.P<0.01 ; \mathrm{R}^{2}=0.28\right)$ and $(\mathrm{B})$ multiple of maintenance based on requirements $(\mathrm{HS}: \mathrm{kg} / \mathrm{d}=-0.23 \mathrm{x}+0.98$; intercept $\mathrm{SE}=1.1$; intercept $P=0.37$; slope $\mathrm{SE}=0.25$; slope $P=0.37$; $\mathrm{R}^{2}=0.01 ; \mathrm{LS}: \mathrm{kg} / \mathrm{d}=0.22 \mathrm{x}-0.88$; intercept $\mathrm{SE}=0.87$; intercept $P$ $=0.31 ;$ slope $\mathrm{SE}=0.22 ;$ slope $\left.P=0.30 ; \mathrm{R}^{2}=0.01\right)$ for cows $(\mathrm{n}=107)$ fed high (HS) and low (LS) starch diets. types of feed more efficiently than others. In their study of broilers selected for high or low digestive efficiency, Rougière et al. (2009) observed that digestive efficiency of the least efficient birds increased when they were presented with a coarse diet that promoted gut retention time. For our study, feeding LS diets resulted in greater differences in digestibility among HRFI and LRFI groups, which might have resulted from LRFI cows having a greater capacity for digestion of low starch, high fiber diets than HRFI cows. Perhaps both groups of cows have similar digestive abilities for high starch diets, which are more readily digestible than high NDF diets. Although we did not characterize the rumen microbial communities of HRFI and LRFI cows, potential differences could account for a portion of the greater NDF digestibility observed for LRFI and not HRFI for LS diets via their influence on ruminal fiber digestion. These differences might be less important for HS diets because postruminal starch digestion compensates for changes in ruminal starch digestion such that apparent total-tract digestibility of starch remains fairly constant (Allen, 2000).

\section{Digestibility Depression as Related to Multiple of Maintenance}

We observed similar relationships of digestibility with $\mathrm{MM}_{\mathrm{I}}$ and DMI as a percentage of MBW for HS and LS so only the relationships of digestibility with $\mathrm{MM}_{\mathrm{I}}$ will be presented and discussed. Multiple of maintenance based on observed DMI $\left(\mathrm{MM}_{\mathrm{I}}\right)$ correlated negatively with digestibilities of DM $(\mathrm{r}=-0.47 ; P<$ $0.01)$, starch $(\mathrm{r}=-0.25 ; P=0.01)$, and $\mathrm{NDF}(\mathrm{r}=$ $-0.43 ; P<0.01$ ) when cows were fed LS diets (Figure 4). However, when cows were fed HS diets, $\mathrm{MM}_{\mathrm{I}}$ was not related to DM or NDF digestibilities $(P>0.20)$, but correlated negatively with starch digestibility $(\mathrm{r}=$ $-0.35 ; P<0.01)$. As $\mathrm{MM}_{\mathrm{I}}$ increased, digestibility of NDF and DM decreased 4.0 and 2.8 units per $\mathrm{MM}_{\mathrm{I}}$ $(P<0.01)$ for LS diets, respectively, but depression in NDF and DM digestibilities associated with $\mathrm{MM}_{\mathrm{I}}$ was not significant for the HS diets $(0.34$ and 0.69 unit decrease per $\mathrm{MM}_{\mathrm{I}}$, respectively; $P=0.79$ and $P=0.23$, respectively). As $\mathrm{MM}_{\mathrm{I}}$ increased, starch digestibility decreased 1.2 and 0.8 percentage units per $\operatorname{MM}_{\mathrm{I}}(P<$ 0.01 and $P=0.01$, respectively) when cows were fed HS and LS diets, respectively. Thus, each unit increase in $\mathrm{MM}_{\mathrm{I}}$ resulted in a $\sim 3$ unit reduction in DM digestibility for LS diets in our study. This was not surprising because it is well established that digestibility decreases as DMI as a multiple of maintenance increases (Tyrrell and Moe, 1975). Our results for LS diets correspond to the assumption that each increase in intake as a multiple of maintenance decreases DM digestibility by $\sim 4$ 
A

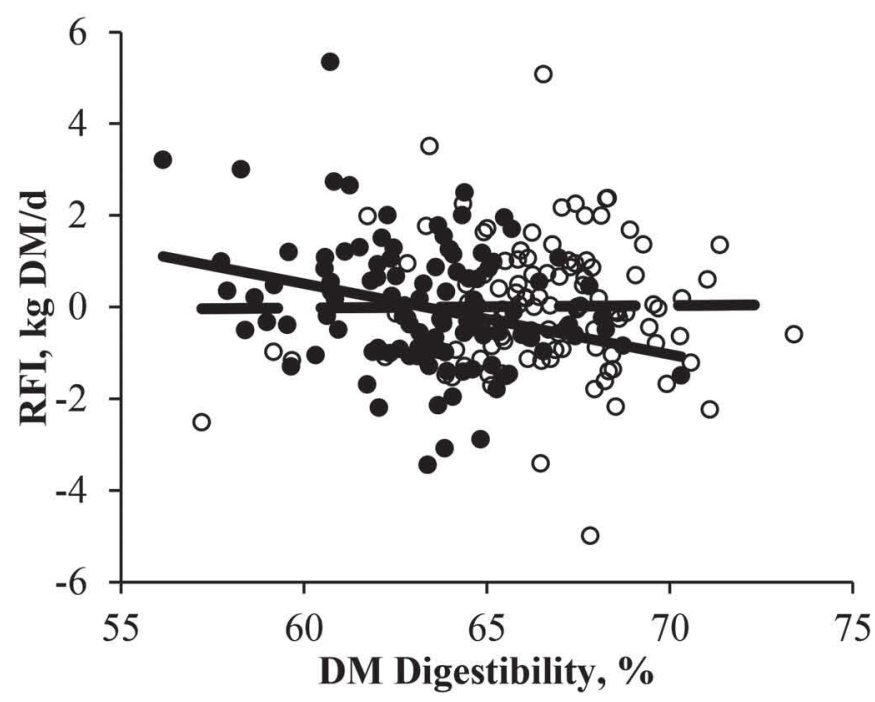

C

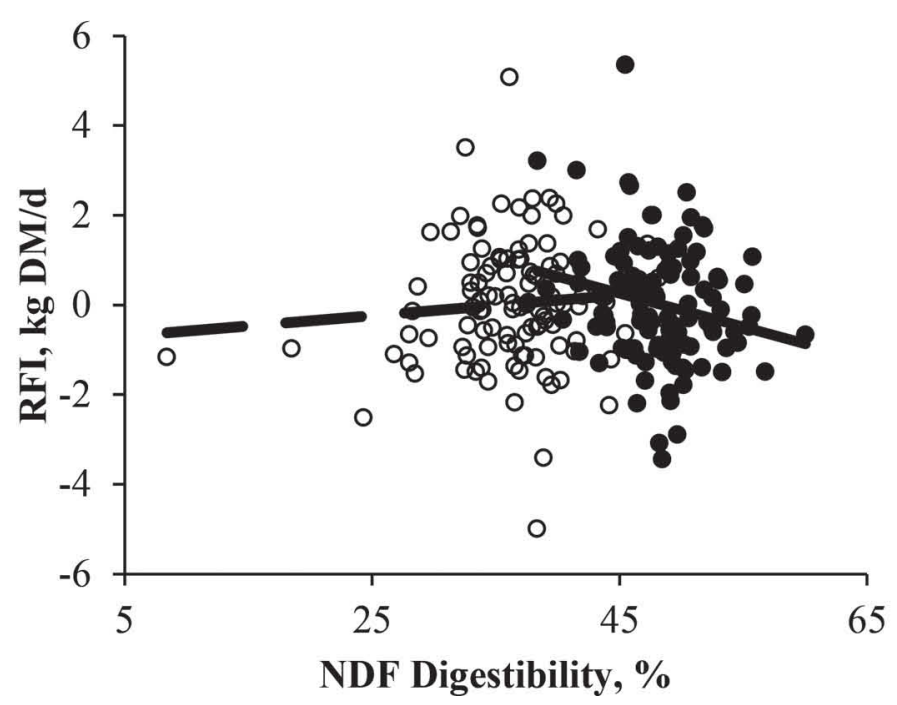

B

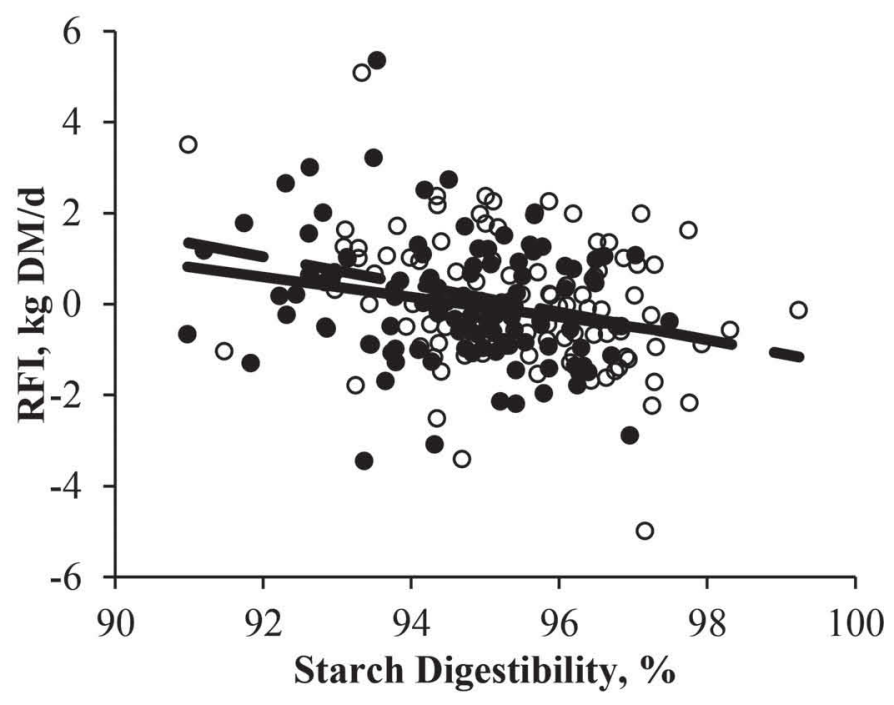

D

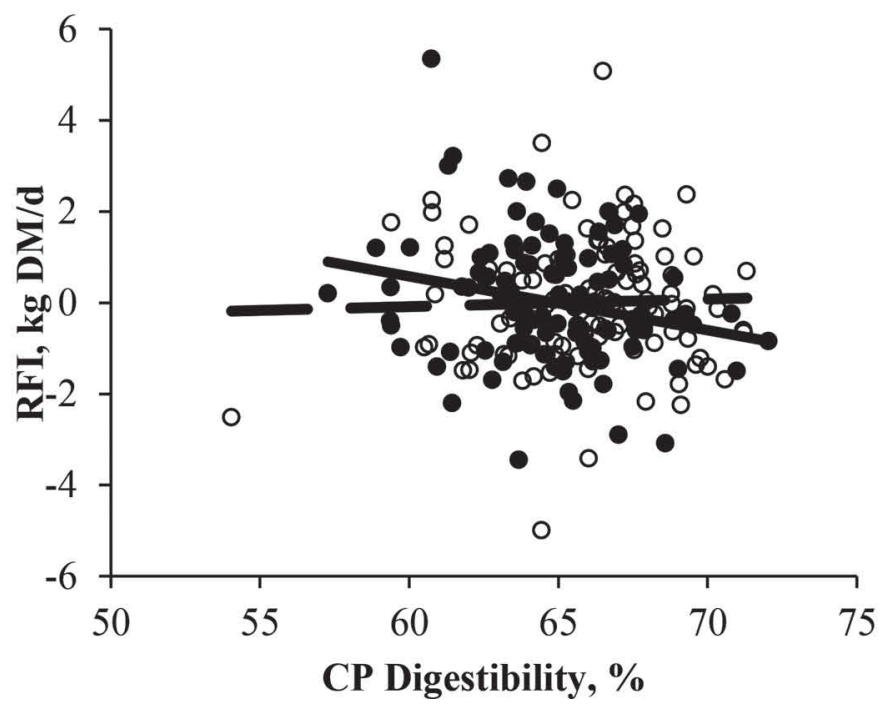

Figure 3. Relationship between residual feed intake (RFI) and digestibility of (A) DM (high starch, HS, open circles, dashed line: \% = $0.0054 \mathrm{x}-0.34$; intercept $\mathrm{SE}=3.7$; intercept $P=0.93$; slope $\mathrm{SE}=0.056$; slope $P=0.92 ; \mathrm{R}^{2}<0.01$; low starch, LS, closed circles, solid line: $\%=-0.15 \mathrm{x}+9.8$; intercept $\mathrm{SE}=3.3$; intercept $P<0.01$; slope $\mathrm{SE}=0.051$; slope $\left.P<0.01 ; \mathrm{R}^{2}=0.09\right)$, (B) starch (HS: \% $=-0.30 \mathrm{x}+29$; intercept $\mathrm{SE}=8.4$; intercept $P<0.01$; slope $\mathrm{SE}=0.088$; slope $P<0.01 ; \mathrm{R}^{2}=0.10 ; \mathrm{LS}: \%=-0.22 \mathrm{x}+21$; intercept $\mathrm{SE}=9.0$; intercept $P$ $=0.02 ;$ slope $\mathrm{SE}=0.095 ;$ slope $\left.P=0.02 ; \mathrm{R}^{2}=0.05\right)$, (C) NDF (HS: $\%=0.023 \mathrm{x}-0.81 ;$ intercept $\mathrm{SE}=0.93 ;$ intercept $P=0.38 ;$ slope SE $=$ 0.025 ; slope $P=0.37 ; \mathrm{R}^{2}=0.01 ; \mathrm{LS}: \%=-0.075 \mathrm{x}+3.6$; intercept $\mathrm{SE}=1.6$; intercept $P=0.03$; slope $\mathrm{SE}=0.034 ;$ slope $P=0.03 ; \mathrm{R}^{2}=0.04$ ), and (D) CP (HS: $\%=0.017 \mathrm{x}-1.1$; intercept SE $=3.1$; intercept $P=0.73$; slope $\mathrm{SE}=0.047$; slope $P=0.73 ; \mathrm{R}^{2}<0.01 ; \mathrm{LS}: \%=-0.12 \mathrm{x}+$ 7.7 ; intercept $\mathrm{SE}=3.2$; intercept $P=0.02$; slope $\mathrm{SE}=0.049$; slope $\left.P=0.02 ; \mathrm{R}^{2}=0.05\right)$ when cows $(\mathrm{n}=107)$ were fed high $(\mathrm{HS})$ and low $(\mathrm{LS})$ starch diets. For HS, partial correlations for DM, starch, NDF, and CP digestibilities after corrections for experiment, cohort, and parity were $0.01(P=0.90),-0.32(P<0.01), 0.09(P>0.30)$, and $0.03(P>0.30)$, respectively. For LS, partial correlations for DM, starch, NDF, and $\mathrm{CP}$ digestibilities after corrections for experiment, cohort, and parity were $-0.30(P<0.01),-0.23(P=0.02),-0.23(P=0.02)$, and -0.23 $(P=0.02)$, respectively.

percentage units (NRC, 2001). Although we expected that digestibility would be depressed by greater levels of DMI due to increased passage rate (Colucci et al., 1982), it was surprising that the depression in digestibility was only significant for the LS diets. The NRC (2001) suggests that the digestibility of diets that are more digestible at $1 \times$ maintenance intake are depressed more per unit increase in $\mathrm{MM}_{\mathrm{I}}$ than that of diets that are less digestible at $1 \times$ maintenance intake. Based on this idea, we expected to see greater digestibility depression per increase in $\mathrm{MM}_{\mathrm{I}}$ for HS than for LS diets because corn grain, the predominant concentrate 
in HS diets, contains more TDN at $1 \times$ maintenance $(89 \%)$ than concentrate ingredients used to replace it to formulate LS diets [soybean hulls $(67 \%)$, whole cottonseed $(77 \%)$, and corn and legume silages $(69 \%$ and $57 \%$, respectively)]; however, this was not the case in our study. The greater digestibility depression for LS diets could be related to the smaller particle size of soybean hulls compared with other NDF sources, and greater feed intake could have reduced their ruminal retention time, enabling a greater proportion to travel out of the gastrointestinal tract undigested (Firkins, 1997). This hypothesis might account for the reduction in both NDF and DM digestibilities that were observed as $\mathrm{MM}_{\mathrm{I}}$ increased for LS diets.

In contrast to $\mathrm{MM}_{\mathrm{I}}$, multiple of maintenance based on production requirements $\left(\mathrm{MM}_{\mathrm{R}}\right)$ was not related to digestibility of starch for HS and LS diets $(P=0.21$; data not shown). However, $\mathrm{MM}_{\mathrm{R}}$ correlated negatively with NDF and DM digestibilities $(\mathrm{r}=-0.31$ and $\mathrm{r}=$ $-0.33 ; P<0.01$; data not shown) for LS diets, with NDF and DM digestibilities decreasing 1.97 and 1.32 units $(P<0.01$; data not shown $)$ per unit increase in $\mathrm{MM}_{\mathrm{R}}$, respectively.

\section{Digestibility Depression and RFI}

Feed intake correlated positively with RFI for both diets, as shown in Figure 2 using intake as a multiple of maintenance. This is to be expected because RFI is the error in the observed versus predicted intake. Because greater intake depresses nutrient digestibility (NRC, 2001, and shown in Figure 4), one thus can expect that RFI will be negatively correlated with digestibility. Digestibilities were modeled as a function of RFI group and experiment plus the effect of $M_{I}$ as a covariate to account for possible effects of intake level on digestibility. Significance of $\mathrm{MM}_{\mathrm{I}}$ but not RFI group in this regression would indicate that differences in digestibility among RFI groups were accounted for by the observed DMI differences. For LS diets, the effect of $\mathrm{MM}_{\mathrm{I}}$ was significant for NDF and DM digestibilities $(P<0.01)$, but the effect of RFI group was not (Table 4 ), suggesting that the previously observed differences between HRFI and LRFI groups fed LS for NDF and DM digestibilities (Table 3) could be due to differences in intake level.

The relationship between DM digestibility and $\mathrm{MM}_{\mathrm{I}}$ by RFI group for HS and LS diets is illustrated in Figure 5. For HS diets, DM digestibility decreased 0.39 $(P=0.82)$ and 1.34 units $(P=0.16)$ for each unit increase in $\mathrm{MM}_{\mathrm{I}}$ for LRFI and HRFI cows, respectively, indicating that digestibility depression associated $\mathrm{MM}_{\mathrm{I}}$ was not significantly different from zero for either RFI group. For LS diets, DM digestibility decreased $1.08(P$
A

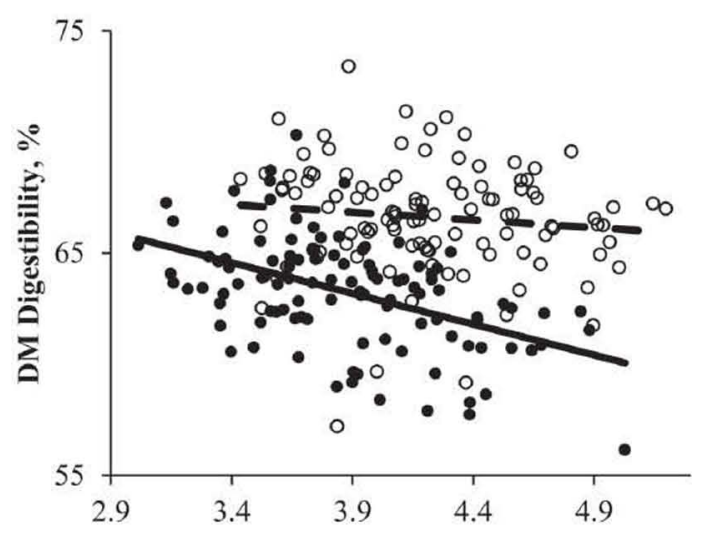

B

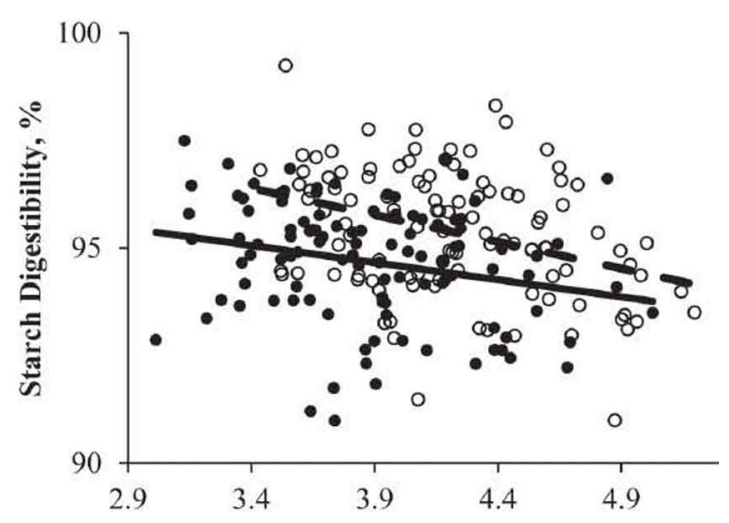

C

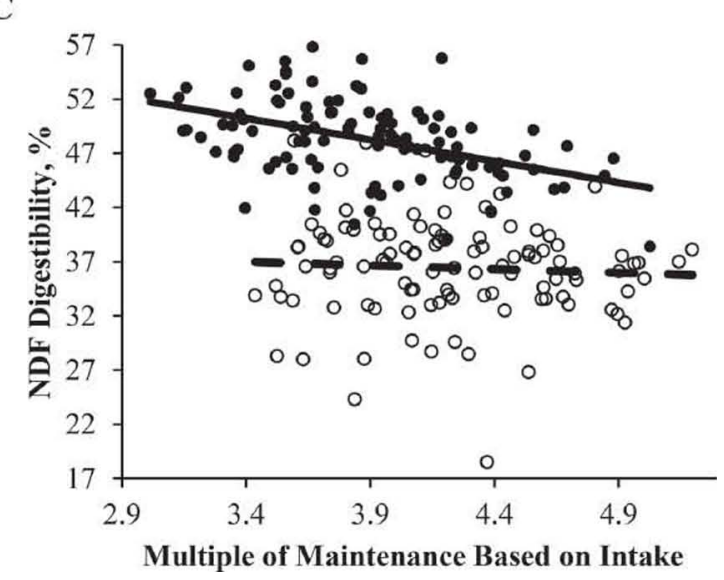

Figure 4. Relationships between multiple of maintenance determined from observed DMI and digestibility of (A) DM (high starch, HS, open circles, dashed line: $\%=-0.69 \mathrm{x}+70$; intercept SE $=2.4$; intercept $P<0.01$; slope $\mathrm{SE}=0.58$; slope $P=0.23 ; \mathrm{R}^{2}=0.01$; low starch, LS, closed circles, solid line: $\%=-2.76 \mathrm{x}+74$; intercept SE $=$ 2.0 ; intercept $P<0.01$; slope $\mathrm{SE}=0.51$; slope $P<0.01 ; \mathrm{R}^{2}=0.22$ ), (B) $\operatorname{starch}(\mathrm{HS}: \%=-1.24 \mathrm{x}+101$; intercept $\mathrm{SE}=1.4$; intercept $P<$ $0.01 ;$ slope $\mathrm{SE}=0.33 ;$ slope $P<0.01 ; \mathrm{R}^{2}=0.12 ; \mathrm{LS}: \%=-0.80 \mathrm{x}+$ 98 ; intercept $\mathrm{SE}=1.2$; intercept $P<0.01$; slope $\mathrm{SE}=0.31$; slope $P=$ $0.01 ; \mathrm{R}^{2}=0.06$ ), and (C) NDF (HS: $\%=-0.34 \mathrm{x}+38$; intercept $\mathrm{SE}$ $=5.3$; intercept $P<0.01 ;$ slope $\mathrm{SE}=1.3$; slope $P=0.79 ; \mathrm{R}^{2}<0.01$; LS: $\%=-3.96 \mathrm{x}+67$; intercept $\mathrm{SE}=3.1$; intercept $P<0.01$; slope $\mathrm{SE}=0.8$; slope $\left.P<0.01 ; \mathrm{R}^{2}=0.19\right)$ for cows $(\mathrm{n}=107)$ fed high $(\mathrm{HS})$ and low (LS) starch diets. 


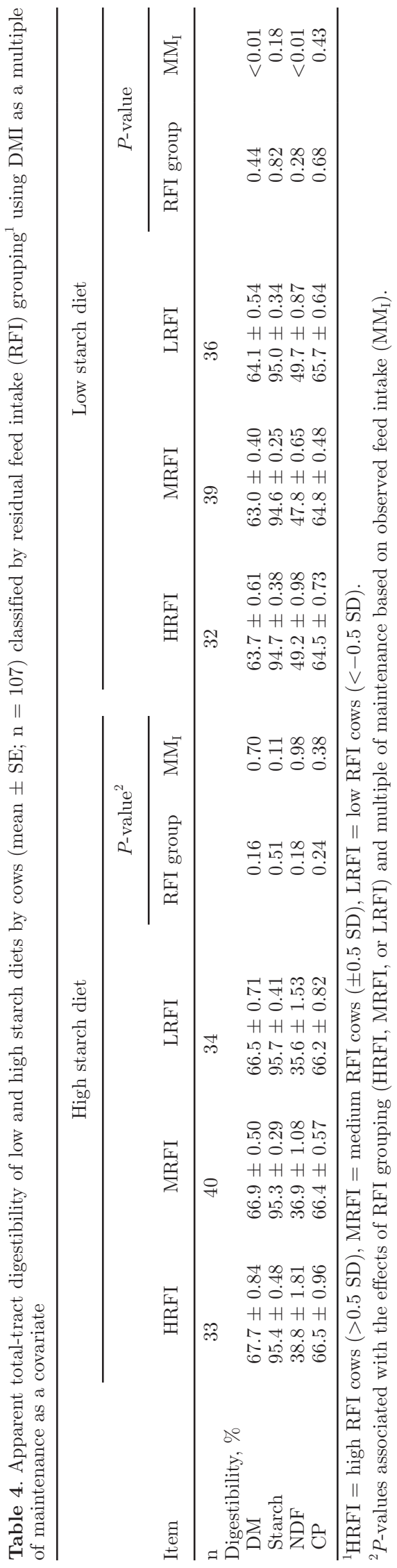

A
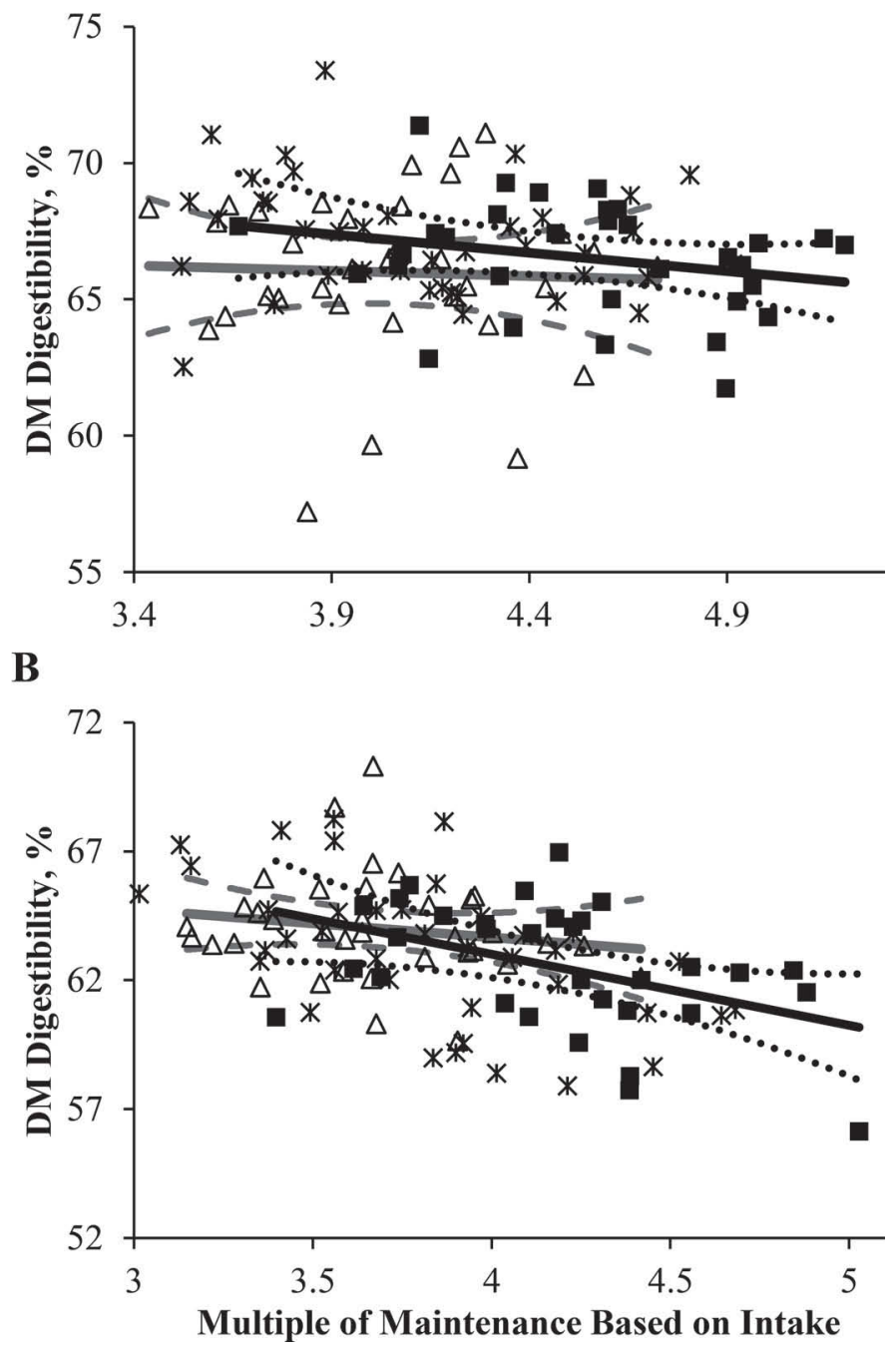

Figure 5. Relationship between DM digestibility and intake on (A) high-starch (HS) and (B) low-starch (LS) diets for cows ranked for RFI as high (HRFI; $>0.5$ SD of the cohort mean), medium (MRFI; $\pm 0.5 \mathrm{SD}$ of the cohort mean), and low (LRFI; $<0.5 \mathrm{SD}$ of the cohort mean). Intake is as a multiple of maintenance calculated from observed feed intake. HRFI cows are shown as closed squares and the solid black lines for both HS $(\%=-1.34 \mathrm{x}+73$; intercept $\mathrm{SE}=4.2$; intercept $P$ $<0.01$; slope $\mathrm{SE}=0.93 ;$ slope $\left.P=0.16 ; \mathrm{R}^{2}=0.06 ; \mathrm{n}=33\right)$ and $\mathrm{LS}(\%$ $=-2.75 \mathrm{x}+74$; intercept $\mathrm{SE}=4.4$; intercept $P<0.01$; slope $\mathrm{SE}=1.0$; slope $P=0.01 ; \mathrm{R}^{2}=0.19 ; \mathrm{n}=32$ ). LRFI cows are shown as open triangles and solid gray line for both HS $(\%=-0.39 \mathrm{x}+68$; intercept SE $=7.0$; intercept $P<0.01$; slope $\mathrm{SE}=1.7$; slope $P=0.82 ; \mathrm{R}^{2}=<0.01$; $\mathrm{n}=34)$ and LS $(\%=-1.08 \mathrm{x}+68$; intercept SE $=4.1 ;$ intercept $P<$ 0.01 ; slope $\mathrm{SE}=1.1$; slope $P=0.34 ; \mathrm{R}^{2}=0.03 ; \mathrm{n}=36$ ). MRFI cows are shown by $\mathrm{X}$ symbols. For both $\mathrm{A}$ and $\mathrm{B}$, the black dotted and gray dashed lines show the $95 \%$ confidence limits for the mean of HRFI and LRFI cows, respectively.

$=0.34)$ and 2.75 units $(P=0.01)$ for each unit increase in $\mathrm{MM}_{\mathrm{I}}$ for LRFI and HRFI cows, respectively, indicating that the degree of digestibility depression per unit increase in $M_{I}$ was more severe for HRFI than LRFI 
cows for LS diets. However, the $95 \%$ confidence intervals for the mean response of HRFI and LRFI groups reveal substantial overlap for both diets (Figure 5).

\section{CONCLUSIONS}

We explored the relationship between RFI and digestibility in lactating dairy cows 4 ways: (1) based on digestibility results for RFI groups with feed intake as a covariate; (2) based on the regression of digestibility on intake as a multiple of maintenance for the 3 RFI groups fed each diet; (3) based on apparent $\mathrm{NE}_{\mathrm{L}}$ values of the diets calculated from animal performance; and (4) based on the inclusion of DM digestibility as a covariate in the regression model to determine RFI (model 2). We conclude that digestibility accounts for at least 9 and up to $31 \%$ of the variation in RFI for mid-lactation cows fed LS diets, but none of the variation when fed HS diets. Increased digestive ability would enable a cow to eat less to maintain the same production and thus have a low RFI (efficient phenotype). However, we recognize that this relationship is not necessarily causative. More work is needed to understand this relationship.

\section{ACKNOWLEDGMENTS}

The authors gratefully acknowledge J. S. Liesman, D. G. Main, and C. L. Preseault (all at the Department of Animal Science at Michigan State University), as well as the staff of the Michigan State University Dairy Cattle Field Laboratory for their assistance in this experiment. Comments and suggestions from N. R. St-Pierre at the Department of Animal Science at The Ohio State University were also very helpful. This project was supported by Agriculture and Food Research Initiative Competitive Grant no. 2011-68004-30340 from the USDA National Institute of Food and Agriculture and by Michigan State University AgBioResearch.

\section{REFERENCES}

Allen, M. S. 2000. Effects of diet on short-term regulation of feed intake by lactating dairy cattle. J. Dairy Sci. 83:1598-1624.

AOAC. 1990. Official Methods of Analysis. 15th ed. Association of Official Analytical Chemists, Gaithersburg, MD.

Beckman, J. L., and W. P. Weiss. 2005. Nutrient digestibility of diets with different fiber to starch ratios when fed to lactating dairy cows. J. Dairy Sci. 88:1015-1023.

Boerman, J. P., S. B. Potts, M. J. VandeHaar, M. S. Allen, and A. L. Lock. 2015a. Milk production responses to a change in dietary starch concentration vary by production level in dairy cattle. J. Dairy Sci. 98:4698-4706.

Boerman, J. P., S. B. Potts, M. J. VandeHaar, and A. L. Lock. 2015b. Effects of partly replacing dietary starch with fiber and fat on milk production and energy partitioning. J. Dairy Sci. 98:7264-7276.

Carberry, C. A., D. A. Kenny, S. Han, M. S. McCabe, and S. M. Waters. 2012. Effect of phenotypic residual feed intake and dietary forage content on the rumen microbial community of beef cattle. Appl. Environ. Microbiol. 78:4949-4958.

Cochran, R. C., D. C. Adams, J. D. Wallace, and M. L. Galyean. 1986. Predicting digestibility of different diets with internal markers: Evaluation of four potential markers. J. Anim. Sci. 63:1476-1483.

Colucci, P. E., L. E. Chase, and P. J. Van Soest. 1982. Feed intake, apparent diet digestibility, and rate of particulate passage in dairy cattle. J. Dairy Sci. 65:1445-1456.

Firkins, J. L. 1997. Effects of feeding nonforage fiber sources on site of fiber digestion. J. Dairy Sci. 80:1426-1437.

Gencoglu, H., R. D. Shaver, W. Steinberg, J. Ensink, L. F. Ferraretto, S. J. Bertics, J. C. Lopes, and M. S. Akins. 2010. Effect of feeding a reduced-starch diet with or without amylase addition on lactation performance in dairy cows. J. Dairy Sci. 93:723-732.

Goering, H. K., and P. J. Van Soest. 1970. Forage Fiber Analysis (Apparatus, Reagents, Procedures, and Some Applications). Agric. Handbook No. 379. US Department of Agriculture-Agricultural Research Service, Washington, DC.

Hach, C. C., B. K. Bowden, A. B. Kopelove, and S. V. Brayton. 1987. More powerful peroxide Kjeldahl digestion method. J. Assoc. Off. Anal. Chem. 70:783-787.

Harris, A. J., J. F. Patience, S. M. Lonergan, J. C. M. Dekkers, and N. K. Gabler. 2012. Improved nutrient digestibility and retention partially explains feed efficiency gains in pigs selected for low residual feed intake. J. Anim. Sci. 90:164-166.

Hernandez-Sanabria, E., L. A. Goonewardene, Z. Wang, O. N. Durunna, S. S. Moore, and L. L. Guan. 2012. Impact of feed efficiency and diet on adaptive variations in the bacterial community in the rumen fluid of cattle. Appl. Environ. Microbiol. 78:1203-1214.

Karkalas, J. 1985. An improved enzymatic method for the determination of native and modified starch. J. Sci. Food Agric. 36:1019 1027.

Koch, R. M., L. A. Swiger, D. Chambers, and K. E. Gregory. 1963. Efficiency of feed use in beef cattle. J. Anim. Sci. 22:486-494.

Lawrence, P., D. A. Kenny, B. Earley, D. H. Crews Jr., and M. McGee. 2011. Grass silage intake, rumen and blood variables, ultrasonic and body measurements, feeding behavior, and activity in pregnant beef heifers differing in phenotypic residual feed intake. J. Anim. Sci. 89:3248-3261.

Luiting, P., E. M. Urff, and M. W. A. Verstegen. 1994. Betweenanimal variation in biological efficiency as related to residual feed consumption. Neth. J. Agric. Sci. 42:59-67.

Merrill, A. and B. Watt. 1973. Energy value of foods. USDA Agriculture Research Service, Agriculture Handbook 74.

Mertens, D. R. 2002. Gravimetric determination of amylase-treated neutral detergent fiber in feeds with refluxing in beakers or crucibles: Collaborative study. J. AOAC Int. 85:1217-1240.

Mignon-Grasteau, S., N. Muley, D. Bastianelli, J. Gomez, A. Péron, N. Sellier, N. Millet, J. Besnard, J. M. Hallouis, and B. Carré. 2004. Heritability of digestibilities and divergent selection for digestion ability in growing chicks fed a wheat diet. Poult. Sci. 83:860-867.

National Research Council. 2001. Nutrient Requirements of Dairy Cattle. 7th ed. Natl. Acad. Press, Washington, DC.

Nkrumah, J. D., E. K. Okine, G. W. Mathison, K. Schmid, C. Li, J. A. Basarab, M. A. Price, Z. Wang, and S. S. Moore. 2006. Relationships of feedlot feed efficiency, performance, and feeding behavior with metabolic rate, methane production, and energy partitioning in beef cattle. J. Anim. Sci. 84:145-153.

Potts, S. B., J. P. Boerman, A. L. Lock, M. S. Allen, and M. J. VandeHaar. 2015. Residual feed intake is repeatable for lactating Holstein dairy cows fed high and low starch diets. J. Dairy Sci. 98:4735-4747.

Richardson, E. C., and R. M. Herd. 2004. Biological basis for variation in residual feed intake in beef cattle. 2. Synthesis of results following divergent selection. Cooperative Research Centre for Cattle and Beef Quality. Aust. J. Exp. Agric. 44:431-440.

Richardson, E. C., R. M. Herd, J. A. Archer, and P. F. Arthur. 2004. Metabolic differences in Angus steers divergently selected for residual feed intake. Aust. J. Exp. Agric. 44:441-452.

Richardson, E. C., R. M. Herd, P. F. Arthur, J. Wright, G. Xu, K. Dibley, and V. H. Oddy. 1996. Possible physiological indicators 
for net feed conversion efficiency in beef cattle. Proc. Aust. Soc. Anim. Prod. 21:103-106.

Rius, A. G., S. Kittelmann, K. A. Macdonald, G. C. Waghorn, P. H. Janssen, and E. Sikkema. 2012. Nitrogen metabolism and rumen microbial enumeration in lactating cows with divergent residual feed intake fed high-digestibility pasture. J. Dairy Sci. 95:50245034 .

Rougière, N., J. Gomez, S. Mignon-Grasteau, and B. Carré. 2009. Effects of diet particle size on digestive parameters in $\mathrm{D}+$ and D- genetic chicken lines selected for divergent digestion efficiency. Poult. Sci. 88:1206-1215.

Tempelman, R. J., D. M. Spurlock, M. Coffey, R. F. Veerkamp, L. E. Armentano, K. A. Weigel, Y. de Haas, C. R. Staples, E. E. Connor, Y. Lu, and M. J. VandeHaar. 2015. Heterogeneity in genetic and nongenetic variation and energy sink relationships for residual feed intake across research stations and countries. J. Dairy Sci. 98:2013-2026.
Tyrrell, H. F., and P. W. Moe. 1975. Effect of intake on digestive efficiency. J. Dairy Sci. 58:1151-1163.

Tyrrell, H. F., and J. T. Reid. 1965. Prediction of the energy value of the milk. J. Dairy Sci. 48:1215-1223.

VandeHaar, M. J., L. E. Armentano, K. Weigel, D. M. Spurlock, R. J. Tempelman, and R. Veerkamp. 2016. Harnessing the genetics of the modern dairy cow to continue improvements in feed efficiency. J. Dairy Sci. 99:4941-4954.

Voelker, J. A., and M. S. Allen. 2003. Pelleted beet pulp substituted for high-moisture corn: 2. Effects on digestion and ruminal digestion kinetics in lactating dairy cows. J. Dairy Sci. 86:3553-3561.

Wildman, E. E., G. M. Jones, P. E. Wagner, R. L. Boman, H. F. Troutt, and T. N. Lesch. 1982. A dairy cow body condition scoring system and its relationship to selected production characteristics. J. Dairy Sci. 65:495-501. 